\title{
Double-tunnel method for treatment of colorectal lesions with severe fibrosis with endoscopic submucosal dissection
}
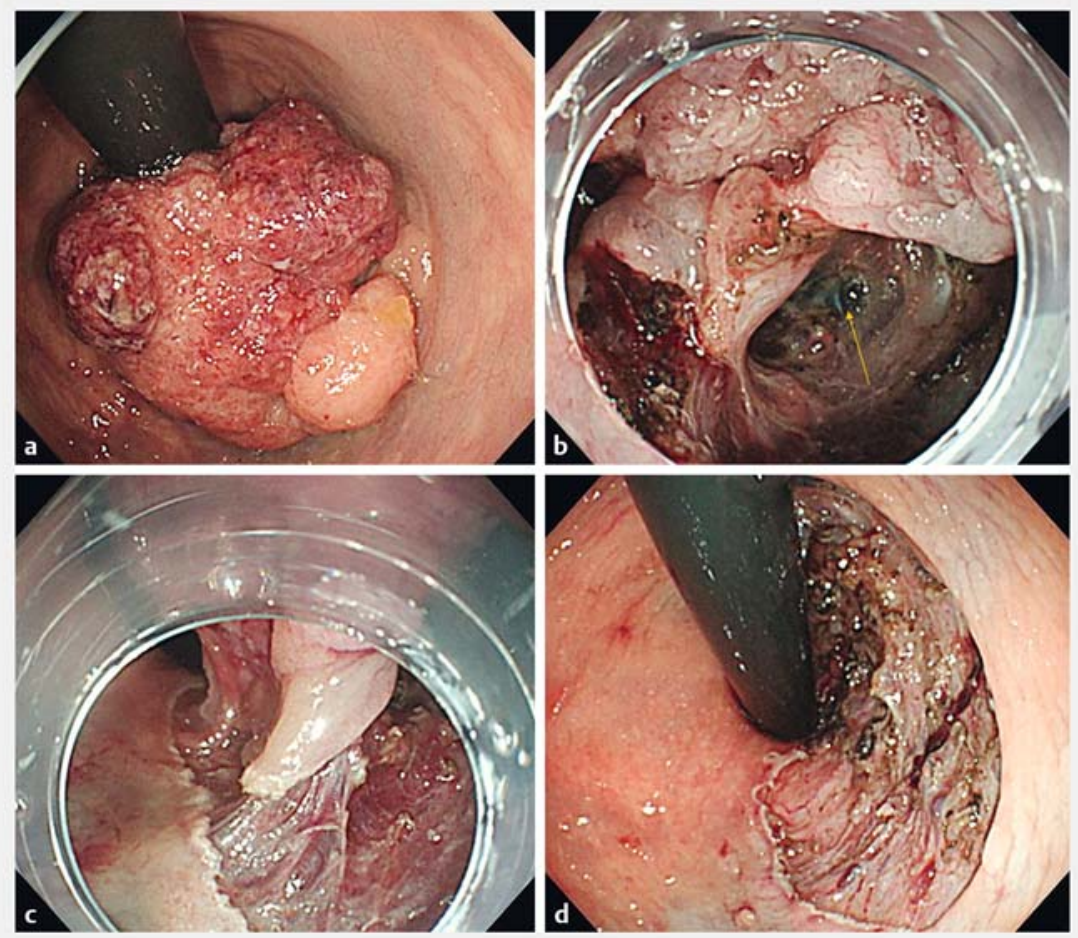

- Fig. 1 Endoscopic images showing: a a protruded lesion in the rectum (60 mm in size) on retroflexed view; $\mathbf{b}$ the entrance of the first tunnel at the anal site (yellow arrow); $\mathbf{c}$ the remaining side of lesion on retroflexed view; $\mathbf{d}$ the appearance after completion of submucosal dissection, which was achieved with no muscle injury.

Endoscopic submucosal dissection (ESD) for gastrointestinal lesions enables en bloc resection with tumor-free margins and is not limited by the lesion size or location. However, en bloc removal of colorectal lesions with severe fibrosis is difficult and requires a longer time [1,2]. We report the successful resection of an early rectal tumor by colorectal ESD with a new method: double-tunnel ESD.

A 68-year-old man was referred to our hospital for treatment of a large subprotruded rectal lesion measuring about $60 \mathrm{~mm}$ in diameter (\$Fig.1 a). He underwent ESD, which was performed using a dual knife (KD-650U; Olympus, Tokyo, Japan), with the patient under deep sedation.
Our plan to achieve en bloc resection of this large sub-protruded lesion, a type of lesion that often has severe fibrosis or displays the muscle-retracting sign during ESD [3], was first to open two different tunnels on each side of the severe fibrosis from the anal side of the lesion ( $>$ Fig.1b). This technique allows good traction to be maintained and an appropriate dissection line to be identified, even in the presence of severe fibrosis. Subsequently, the two tunnels were connected ( $\vee$ Video 1 ). Finally, mucosal and submucosal dissections were performed from both sides to open the lesion from the lower side against gravity ( $>$ Fig. 1 c). After this, the lesion was completely resected en bloc without any complications

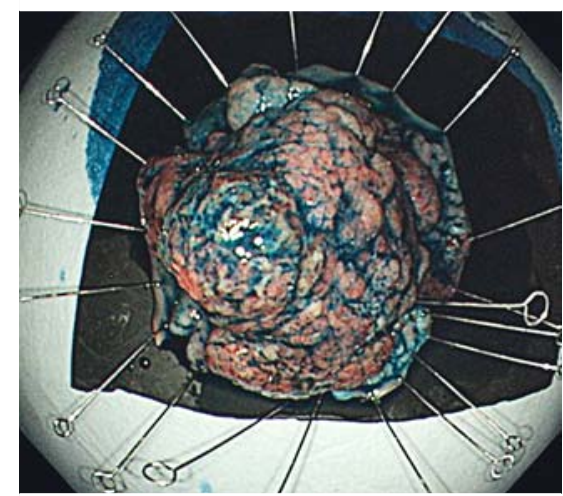

- Fig. 2 The opened specimen revealed submucosally invasive carcinoma, with negative margins, measuring $59 \times 50 \mathrm{~mm}$.

( $\triangleright$ Fig.1d). The tumor was $59 \times 50 \mathrm{~mm}$ in size; histological examination revealed a submucosally invasive carcinoma, with all the margins being tumorfree ( $>$ Fig. 2 ).

ESD using the double-tunnel method can achieve reliably efficient and safe resection of colorectal lesions with severe fibrosis or displaying the muscle-retracting sign.

Endoscopy_UCTN_Code_TTT_1AQ_2AD

Competing interests

None

The authors

Hideyuki Chiba ${ }^{1}$, Ken Ohata², Maiko Takita², Jun Tachikawa', Keiichi Ashikari' ${ }^{1}$, Toru Goto ${ }^{1}$, Atsushi Nakajima ${ }^{3}$

1 Department of Gastroenterology, Omori Red Cross Hospital, Tokyo, Japan

2 Department of Gastroenterology, NTT Medical Center Tokyo, Tokyo, Japan

3 Department of Gastroenterology and Hepatology, Yokohama City University school of Medicine, Yokohama, Japan 


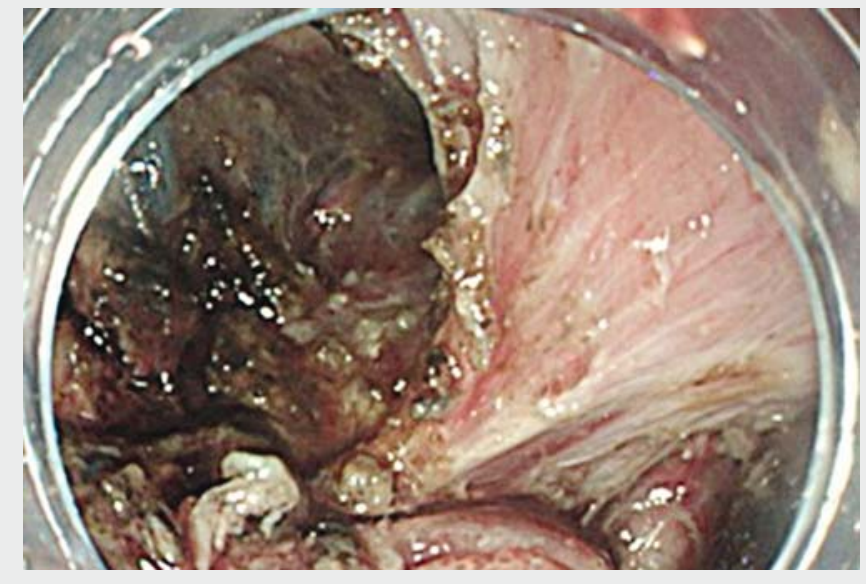

Video 1 Colorectal endoscopic submucosal dissection with the double-tunnel method is used to resect a lesion with severe fibrosis efficiently and safely because good traction is maintained and an appropriate dissection line can be identified.

\section{Corresponding author}

\section{Hideyuki Chiba, MD, PhD}

Department of Gastroenterology, Omori Red Cross Hospital , 4-30-1, Chuo, Ota-Ku,

Tokyo, 143-8527, Japan

h.chiba04@gmail.com

\section{References}

[1] Matsumoto A, Tanaka S, Oba S et al. Outcome of endoscopic submucosal dissection for colorectal tumors accompanied by fibrosis. Scand J Gastroenterol 2010; 45: $1329-1337$
[2] Chiba H, Tachikawa J, Kurihara D et al. Safety and efficacy of simultaneous colorectal ESD for large synchronous colorectal lesions. Endosc Int Open 2017; 5: E595-E602

[3] Toyonaga T, Tanaka S, Man-I M et al. Clinical significance of the muscle-retracting sign during colorectal endoscopic submucosal dissection. Endosc Int Open 2015; 3: E246E251

\section{Bibliography}

DOI https://doi.org/10.1055/a-0599-0401

Published online: 9.5.2018

Endoscopy 2018; 50: E168-E169

(c) Georg Thieme Verlag KG

Stuttgart · New York

ISSN 0013-726X

\section{ENDOSCOPY E-VIDEOS}

https://eref.thieme.de/e-videos

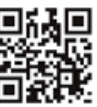

Endoscopy E-Videos is a free access online section, reporting on interesting cases and new techniques in gastroenterological endoscopy. All papers include a high quality video and all contributions are freely accessible online.

This section has its own submission website at

https://mc.manuscriptcentral.com/e-videos 